\title{
Effects of Prostaglandin Analogue Iloprost Treatment on Distant Organ Damage Following Ovarian Ischemia/Reperfusion Injury in Rats: An Experimental Study
}

\author{
Öznur Uludağ ${ }^{1}$, Mevlüt Doğukan ${ }^{2}$, Mehmet Duran ${ }^{3}$, Ebru Annac ${ }^{4}$ \\ 1. Anesthesiology and Reanimation, Adıyaman University Faculty of Medicine, Adıyaman, TUR 2. Anesthesiology and \\ Reanimation, Adiyaman University Faculty of Medicine, Adiyaman, TUR 3. Anesthesiology and Reanimation, \\ Adiyaman University Education and Research Hospital, Adiyaman, TUR 4. Histology and Embryology, Adıyaman \\ University Faculty of Medicine, Adiyaman, TUR
}

Corresponding author: Öznur Uludağ, uludagoznur@gmail.com

\section{Abstract}

\section{Background}

Ischemia/reperfusion (I/R) injury causes oxidative stress, which, in turn, may impair the oxidant/antioxidant balance in tissues and cause damage to the tissues. The local effects of I/R injury can be typically observed in the related organ while systemic effects can be observed predominantly in the heart, brain, lung, and kidney. In this study, we aimed to evaluate the effects of iloprost on heart tissues after an ovarian I/R injury in an experimental rat model.

\section{Materials and methods}

A total of 32 female Sprague Dawley rats were used for the experiment. The rats were divided into four groups with eight rats each: Group I, control group; Group II, ischemia group; Group III, I/R group; Group IV, $\mathrm{I} / \mathrm{R}+\mathrm{iloprost}$ group. Surgical intervention was performed in each group and after the procedures, heart tissues were obtained and examined histopathologically.

\section{Results}

No significant pathological finding was found in Group I and II while degeneration of muscle fibers and interstitial edema was observed in group III and dilation of the vessels was detected in Group IV. No fibrosis or inflammation was observed in any group.

\section{Conclusion}

Iloprost provided protection against I/R injury and thus may be an alternative treatment for I/R injury.

Received 10/09/2019

Review began 10/16/2019

Review ended 06/18/2020

Published 06/19/2020

() Copyright 2020

Uludağ et al. This is an open access

article distributed under the terms of the Creative Commons Attribution License CC-BY 4.0., which permits unrestricted use, distribution, and reproduction in any medium, provided the original author and source are credited.
Categories: Anesthesiology

Keywords: rat, iloprost, ischemia / reperfusion model, distant organ, heart

\section{Introduction}

Ischemia, or insufficiency of perfusion, is defined as restricted blood supply to tissues, causing a shortage of oxygen and other metabolites necessary for cellular metabolism. Acute ischemia is a clinical problem with a high morbidity and mortality risk [1]. The severity of ischemic damage is proportional to the duration and amount of hypoperfusion and varies according to cell type, sensitivity, blood requirement, and metabolism. In ischemia, lack of oxygen causes a shift to anaerobic metabolism, leading to impaired removal of metabolic waste products. Moreover, the release of cellular energy stores and the accumulation of toxic metabolites result in cell death [2]. Blood flow in ischemic tissue should be restored for cell regeneration and the removal of toxic metabolites. However, reperfusion of ischemic tissue itself paradoxically causes tissue damage, leading to the onset of a series of events [3].

Ovarian torsion is the rotation of the ovary around its own ligaments and is typically treated by detorsion [4]. Following detorsion, ovarian tissues are irrigated with oxygenated blood. Ischemia stimulates the migration of polymorphonuclear leukocytes and platelets into the ischemic tissue, thereby increasing the formation of inflammatory cytokines and free oxygen radicals. In turn, free oxygen radicals cause mitochondria and peroxidation of lipids in cell membranes, ultimately leading to ischemia/reperfusion (I/R) injury in ischemic tissues through the activation of leukocytes and reactive oxygen metabolites [5].

Literature indicates that I/R injury can be more harmful than ischemic damage [5-6]. Moreover, I/R injury leads to both local and systemic effects, of which local effects are observed in the affected organ 
and systemic effects can be observed predominantly in the heart, brain, lung, and kidney [7]. The distant organ effects of I/R injury may lead to the development of septic shock and multiple organ dysfunction syndrome (MODS). Central to I/R injury are the free oxygen radicals resulting from the oxygenation of the tissue during reperfusion. Moreover, inflammatory response characterized by leukocyte activation plays the most important role in distant organ damage [8-9].

Prostacyclins are arachidonic acid metabolites used in the treatment of peripheral arterial diseases due to their vasodilatory and antiaggregant effects. Iloprost is a prostacyclin derivative that exerts its vasodilatory effects through prostaglandin pathways. Moreover, iloprost inhibits leukocyte activation and adhesion by reducing leukotriene, free oxygen radicals, and proteolytic enzyme secretion, thereby exerting its endothelial protective effect [10].

In the present study, we hypothesized that the heart tissues are affected by I/R injury occurring in any organ. Accordingly, we aimed to investigate the effects of iloprost on heart tissues through an experimental ovarian I/R model in rats.

\section{Materials And Methods}

\section{Animals}

A total of 32 female Sprague Dawley rats aged eight to 10 months, weighing 280-300 g were used in the study. All animals were exposed to a 12/12-hour light/dark cycle with the ambient temperature maintained at $22 \pm 2{ }^{\circ} \mathrm{C}$. All the experimental procedures were approved by the Adiyaman University Experimental Animal Research and Application Center Ethics Committee (Approval No: 13.12.2018/2018-30). All applicable international, national, and institutional guidelines for the care and use of animals were followed [11].

\section{Experimental groups}

The 32 rats were divided into four groups with eight rats each:

Group I (Control Group)

Midline laparotomy was performed alone, without any additional surgical intervention. Heart tissue specimens were collected for histopathological examination.

Group II (Ischemia Group)

A 2-cm midline incision was made in the lower abdomen. The adnexa containing the tube and ovarian tissues was rotated 360 degrees clockwise (torsion) to interrupt ovarian blood flow and then was fixed to the abdominal wall. The heart was surgically removed after three hours of ischemia.

Group III (I/R Group)

The rats underwent three hours of ischemia via ovarian torsion with subsequent three hours of detorsion (reperfusion period). After a total of six hours, the heart was surgically removed.

Group IV (I/R + Iloprost Infusion Group)

The rats underwent three hours of ischemia followed by an infusion of iloprost $\left(10 \mu \mathrm{g} / \mathrm{kg}\right.$, IV; Ilomedin ${ }^{\circledR}$ (Schering, Berlin, Germany)) initiated 10 min before reperfusion of the catheter (intravenous (IV) cannula 24 g (yellow) $19 \mathrm{~mm}$ x 50 (Braun Vasofix; B. Braun Medical Ltd, Sheffield, UK) inserted into the jugular vein. Iloprost infusion was continued throughout the first 60 minutes of reperfusion, followed by reperfusion for two hours. After a total of six hours, the heart was surgically removed.

In each group, the rats were sacrificed after the completion of surgical procedures. Subsequently, heart tissues were fixed in $10 \%$ formaldehyde solution for histopathological examination.

\section{Histopathological evaluation}

Heart tissues were fixed in $10 \%$ formaldehyde solution and routine histological tissue monitoring was performed with alcohol, xylene, and Paraplast. Tissue samples were embedded in paraffin and then the specimens were sectioned into 5-mm-thick sections. The sections were stained with hematoxylin and eosin (H\&E) and Masson's trichrome (MT) staining for histopathological evaluation. Stained sections were examined using a microscope attached to the Carl Zeiss Axiocam (Germany) ERc5 digital camera.

\section{Results}




\section{Cureus}

The examination of the control group revealed dense muscle fibers, no interstitial edema in the connective tissues between the fibers, no sign of dilation or hemorrhagic areas, and no pathological findings in muscle tissues (Figure 1).
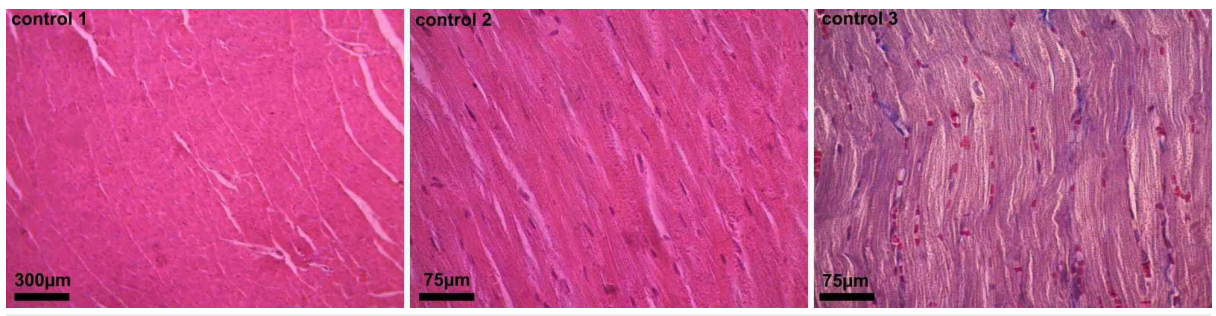

FIGURE 1: Light microscopy image of heart tissues of the control group (x10 - H\&E staining, x40 - H\&E staining, and x40 - Masson trichrome staining, respectively)

Normal heart tissue image was observed

H\&E: hematoxylin and eosin

In the examination of Group II, the three layers of the heart (endocardium, myocardium, and epicardium) and normal-appearing heart tissue were observed (Figure 2; a1, a2, a3). In the evaluation of group III, myocardial damage, degeneration of muscle fibers, and interstitial edema were observed (Figure 2; b1, b2, b3). On the other hand, the evaluation of Group IV revealed the dilation of the vessels (Figure 2; c1, c2, c3).
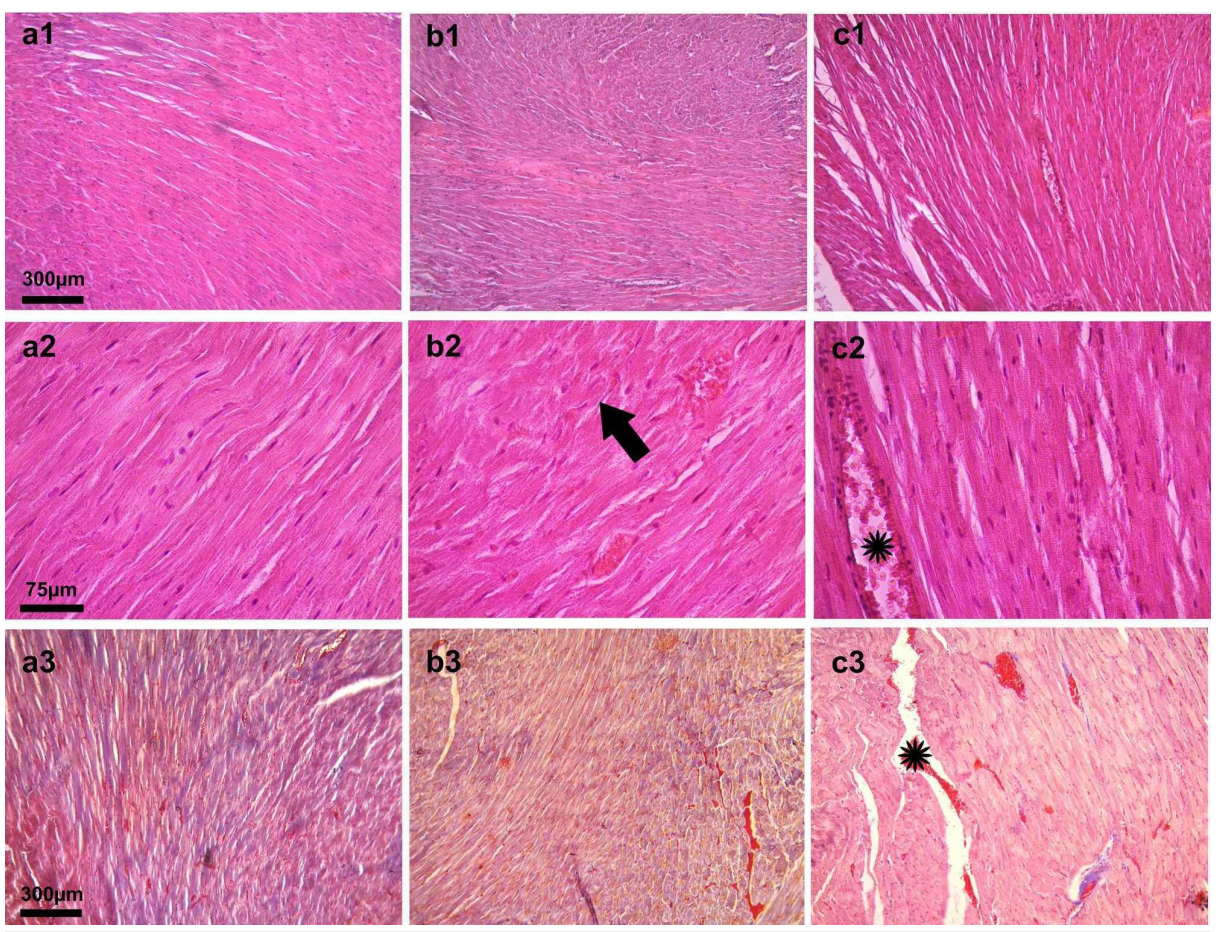

FIGURE 2: Light microscopic image of heart tissues of the ischemia group, I/R group, and I/R plus iloprost group, respectively

a1, b1, and c1: Light microscopy image (x10, H\&E staining) of the ischemia group, I/R group, and I/R plus iloprost group, respectively

a2, b2, and c2: Light microscopy image ( 40 , H\&E staining) of ischemia group, l/R group, and I/R plus iloprost group, respectively

a3, b3, and c3: Light microscopy image (x10, Masson's trichrome staining) of ischemia group, l/R group, and I/R plus iloprost group, respectively

Black arrow: deformed muscle fibers; star: dilated vein; H\&E: hematoxylin and eosin 


\section{Cureus}

The examination of the ischemia group (Group II) revealed normal heart tissue with dense muscle fibrils and a small number of connective tissues. The muscle fibrils had abundant sarcoplasm. Moreover, the nuclei of the cells were centrally located and were single and oval in shape. The connective tissues were remarkably thin and transparent (Figure 3; a4, a5).
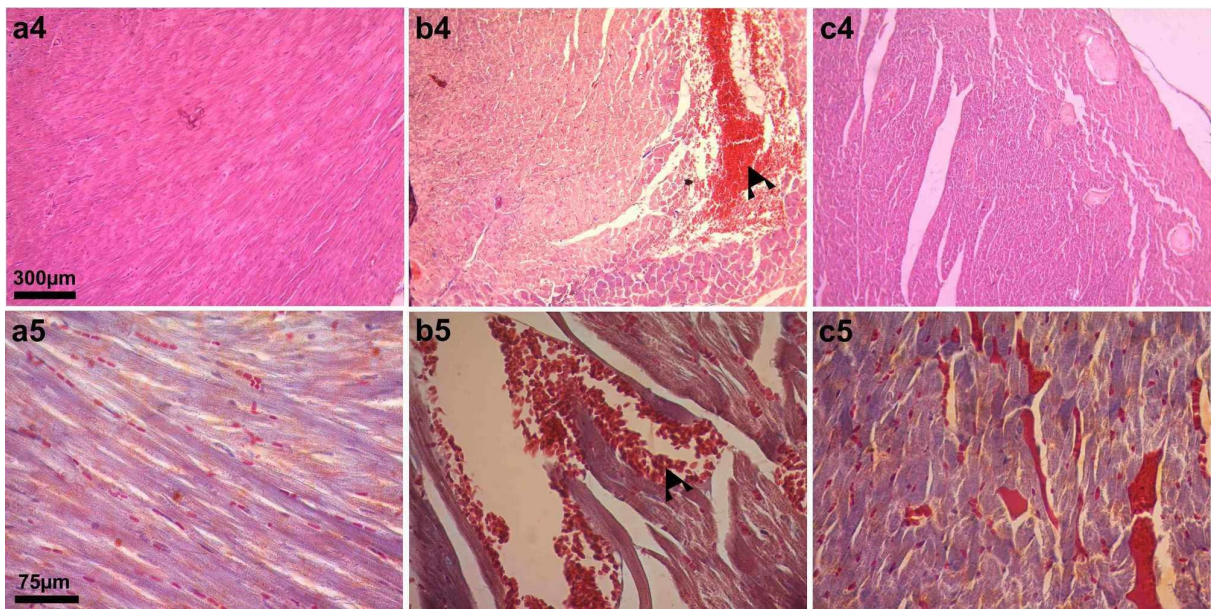

\section{FIGURE 3: Light microscopic image of heart tissues belonging to the ischemia group, I/R group, and I/R plus iloprost group, respectively}

a4, b4, and c4: Light microscopy image (x10, H\&E staining) of ischemia group, I/R group, and I/R plus iloprost group, respectively

a5, b5, and c5, Light microscopy image (x40, Masson's trichrome staining) of ischemia group, l/R group, and I/R plus iloprost group, respectively

Black arrowhead: hematological fields; H\&E: hematoxylin and eosin: I/R: ischemia/reperfusion

In the I/R group (Group III), a degeneration of muscle fibers was observed when compared to the ischemia group. Additionally, interstitial edema and hemorrhagic areas were observed (Figure 3; b4, b5).

In the detailed examination of the I/R + iloprost group (Group IV), it was noted that the muscle fibril structure was generally similar to that of the ischemia group (Group II). In addition, vascular dilatations were observed (Figure 3; c4, c5). However, no fibrosis or inflammation was observed in any group.

\section{Discussion}

A critical consequence of $\mathrm{I} / \mathrm{R}$ is distant organ damage. Although the protective effect of iloprost on local organ damage has been shown experimentally, its effects on the distal organ in I/R injury have not been investigated sufficiently. The heart and lungs are the first organs to be affected by I/R injury [12]. In addition, I/R injury may lead to MODS or septic shock, which share similar clinical features, occur via inflammatory mediators, and potentially cause high mortality. Reperfusion also produces increased leukocyte traffic and vascular dysfunction in distant organs via complement system activation [13].

The morphological changes associated with prolonged ischemia followed by reperfusion include cellular swelling, membrane depolarization, loss of pinocytotic vesicles, endothelial basement membrane separation, and adherence of active leukocytes to the endothelial cell surface. Moreover, volume-controlled anion duct dysfunction is reported as the most important factor affecting volume swelling due to I/R injury [14].

The mainstay treatment of ischemia is increasing coronary blood flow, which in turn may lead to reperfusion damage. Therefore, once ischemia is detected, utmost care should be taken to prevent or minimize reperfusion injury. Currently, there are numerous clinical and pharmacological trials aiming to reduce reperfusion injury. Iloprost is a prostacyclin analog that can reduce I/R injury with its direct vasodilatory, cytoprotective, membrane stabilization, and antiaggregant and anti-inflammatory effects. Iloprost is also effective in local organ damage caused by $\mathrm{I} / \mathrm{R}$ and has been shown to reduce renal I/R injury and to provide protection against lung injury caused by skeletal muscle I/R [15-17]. 
that iloprost showed myocardial protective effects independently of the onset of ischemia. The studies also showed that iloprost preserved myocardial function in the myocardial I/R model and that the infarct area decreased more as the reperfusion period prolonged by iloprost application [18]. Iloprost has also been shown to be a potent vasodilator that particularly affects the dilation of arterioles and venules and to reduce the increased vascular permeability in the microcirculation [19]. Moreover, iloprost has been demonstrated to reduce oxidative muscle damage after I/R and this effect has been associated with decreased neutrophil activation, chemotaxis, and superoxide anion production [20].

In our study, no pathology was detected in the heart as a distant organ in the control and ischemia groups. In the remaining groups, however, degeneration of the muscle fibers and interstitial edema was observed in the $\mathrm{I} / \mathrm{R}$ group and vasodilation was observed in the $\mathrm{I} / \mathrm{R}+$ iloprost group. These findings implicate that iloprost decreases heart tissue injury secondary to ovarian I/R injury and that endothelium-dependent vasodilation is an indicator of I/R injury and iloprost treatment plays an important role in maintaining vasodilatory response.

\section{Limitations of the study}

The study only included a histological evaluation of I/R injury and did not include any biochemical and immunohistochemical evaluation, which might limit the generalizability of our results. However, we consider that future studies investigating the effects of iloprost on I/R injury in different tissues may benefit from the findings of our study.

\section{Conclusions}

In the current study, iloprost was found to be histopathologically effective in I/R-induced distant organ damage in rats and may be an alternative treatment for I/R injury. Further clinical studies are needed to substantiate our findings.

\section{Additional Information \\ Disclosures}

Human subjects: All authors have confirmed that this study did not involve human participants or tissue. Animal subjects: Adiyaman University Experimental Animal Research and Application Center Issued protocol number 13.12.2018/2018-30. Conflicts of interest: In compliance with the ICMJE uniform disclosure form, all authors declare the following: Payment/services info: All authors have declared that no financial support was received from any organization for the submitted work. Financial relationships: All authors have declared that they have no financial relationships at present or within the previous three years with any organizations that might have an interest in the submitted work. Other relationships: All authors have declared that there are no other relationships or activities that could appear to have influenced the submitted work.

\section{References}

1. Siemionow M, Arslan E: Ischemia/reperfusion injury: a review in relation to free tissue transfers . Microsurgery. 2004, 24:468-475. 10.1002/micr.20060

2. Carden DL, Granger DN: Pathophysiology of ischaemia-reperfusion injury. J Pathol. 2000, 190:255-266. 10.1002/(SICI)1096-9896(200002)190:3<255::AID-PATH526>3.0.CO;2-6

3. Collard CD, Gelman S: Pathophysiology, clinical manifestations and prevention of ischemia-reperfusion injury. Anesthesiology. 2001, 94:1133-1138. 10.1097/00000542-200106000-00030

4. Huang C, Hong M, Ding D: A review of ovary torsion. Tzu Chi Med J. 2017, 29:143-147. 10.4103/tcmj.tcmj_55_17

5. Abakay U, Soylu S, Göksel S, et al.: Role of pentoxifylline and iloprost in the prevention of ischemiareperfusion injury in an experimental model of intestine ischemia-reperfusion in rats [Article in Turkish]. Ulus Travma Acil Cerrahi Derg. 2018, 24:398-404. 10.5505/tjtes.2018.22227

6. Çevirme D, Adademir T, Kafalı Başaran E, et al.: Comparison between iloprost and alprostadil for protection against ischemia/reperfusion injury in a rat model. Turk J Med Sci. 2018, 14:661-669. 10.3906/sag-1710-74

7. Haimovici H: Metabolic complications of acute arterial occlusions and skeletal muscle ischemia: myonephropatic metabolic syndrome. Haimovici's Vascular Surgery Principal and Techniques, 4th Edition. Blackwell Science, Cambridge, UK; 1996. 509-530.

8. Blaisdell FW: The pathophysiology of skeletal muscle ischemia and the reperfusion syndrome: a review . Cardiovasc Surg. 2002, 10:620-630.

9. Tassiopoulos AK, Carlin RE, Gao Y, et al.: Role of nitric oxide and tumor necrosis factor on lung injury caused by ischemia-reperfusion of the lower extremities. J Vasc Surg. 1997, 26:647-665. 10.1016/S07415214(97)70065-X

10. Rademaker M, Cooke ED, Almond NE, Beacham JA, Smith RE, Mant TG, Kirby JD: Comparison of intravenous infusions of iloprost and oral nifedipine in treatment of Raynaud's phenomenon in patients with systemic sclerosis: a double blind randomised study. BMJ. 1989, 4:561-564. 10.1136/bmj.298.6673.561

11. Uludağ O: History and importance of ethical rules in animal experiment studies [Article in Turkish] . Sağlık Bilimleri Derg. 2019, 5:1401-1413.

12. Carden DL, Granger DN: Pathophysiology of ischaemia-reperfusion injury. J Pathol. 2000, 190:255-266. 10.1002/(SICI)1096-9896(200002)190:3<255::AID-PATH526>3.0.CO;2-6 


\section{Cureus}

13. Foulds S, Mireskandari M, Kalu P, Jackson W, Cheshire NJ, Mansfield AO, Schachterb M: Visceral ischemia and neutrophil activation in sepsis and organ dysfunction. J Surg Res. 1998, 75:170-176. 10.1006/jsre.1998.5276

14. Romanenko VG, Davies PF, Levitan I: Dual effect of fluid shear stress on volume-regulated anion current in bovine aortic endothelial cells. Am J Physiol Cell Physiol. 2002, 282:708-718. 10.1152/ajpcell.00247.2001

15. Yakut N, Yasa H, Lafci BB, et al.: The influence of levosimendan and iloprost on renal ischemia reperfusion: an experimental study. Interact Cardiovasc Thorac Surg. 2008, 7:235-239. 10.1510/icvts.2007.161356

16. Ozcan AV, Sacar M, Aybek H, et al.: The effect of iloprost and vitamin C on kidney as a remote organ after ischemia reperfusion of lower extremities. J Surg Res. 2007, 140:20-26. 10.1016/j.jss.2006.04.031

17. Erer D, Dursun AD, Oktar GL, et al.: The effects of iloprost on lung injury induced by skeletal muscle ischemia-reperfusion. Bratisl Med J. 2014, 115:405-410. 10.4149/BLL_2014_080

18. Farber NE, Pieper GM, Thomas JP, Gross GJ: Beneficial effects of iloprost in the stunned canine myocardium. Circ Res. 1988, 62:204-215. 10.1161/01.res.62.2.204

19. Blebea J, Cambria RA, DeFouw D, Feinberg RN, Hobson RW II, Duran WN: Iloprost attenuates the increased permeability in skeletal muscle after ischemia and reperfusion. J Vasc Surg. 1990, 12:665-666. 10.1067/mva.1990.25129

20. Bozkurt AK: Alpha-tocopheral (Vitamin E) and iloprost attenuate reperfusion injury in skeletal muscle ischemia/reperfusion injury. J Cardiovasc Surg. 2002, 43:693-696. 